\title{
Comparative study of IUCD inserted intracesarean and after vaginal delivery
}

\section{Archana Goyal, Rekha Wadhwani*}

Department of Obstetrics and Gynecology, Gandhi Medical College Bhopal, Madhya Pradesh, India

Received: 08 March 2018

Accepted: 03 April 2018

\section{*Correspondence:}

Dr. Rekha Wadhwani,

E-mail: drrekhaw@yahoo.co.in

Copyright: (C) the author(s), publisher and licensee Medip Academy. This is an open-access article distributed under the terms of the Creative Commons Attribution Non-Commercial License, which permits unrestricted non-commercial use, distribution, and reproduction in any medium, provided the original work is properly cited.

\begin{abstract}
Background: In view of high rate of unintended pregnancy in our country, particularly in post-partum women, there is a need for reliable, effective, long-term contraception such as intrauterine device (IUD) in post-partum women. The present study was planned to evaluate the safety and efficacy of immediate post-partum IUD insertion in women delivering vaginally or by caesarean section.

Methods: The women recruited had CuT 380A insertion immediately after delivery of placenta in vaginal or caesarean delivery. Women having post-partum haemorrhage (PPH), anaemia, pre-labour rupture of membranes $>18$ $\mathrm{h}$, obstructed labour and distorted uterine cavity by fibroid or by congenital malformation were excluded from the study. The women were followed up at 6 weeks after delivery.

Results: A total of 500 women were included in the study. The present study shows that expulsion rate was more in postplacental insertion group i.e. $13.2 \%$ while among intracaesarean group it was $6.8 \%$ and this difference was statistically significant. Removal rate of PPIUCD (Post-partum Intrauterine Contraceptive device) was higher in postplacental insertion i.e.43 (17.2\%) cases whereas in intracaesarean insertion removal rate was $8.4 \%$. Most common cause of removal of PPIUCD in our study was pelvic pain and menstrual disturbances.

Conclusions: Thus, from our study it is concluded that PPIUCD is safe, convenient, cost effective, reversible and long-term birth spacing method. It should be part of a maternal/newborn/reproductive health package.
\end{abstract}

Keywords: Contraception, Expulsion family planning, PPIUCD

\section{INTRODUCTION}

Family planning is important not only for population stabilization,but it has been increasingly realized that family planning is central to improve maternal and newborn survival and health.India accounts for more than $20 \%$ of global maternal and child deaths, most of them preventable. ${ }^{1}$ In spite of availability of wide range of contraceptives, the unmet need for family planning in India is estimated to be $21.3 \%$ by DLHS III survey. ${ }^{2}$ The common reasons for unmet need are unsatisfactory services, lack of information, and fear about side effects of contraceptive methods. Studies showed that pregnancies taking place within 24 months of previous birth have higher risk of adverse outcome like abortion, premature labour, postpartum haemorrhage, low birth weight babies, fetal loss, and maternal death., ${ }^{3,4}$ The recommended interval before attempting the next pregnancy is at least 24 months in order to reduce the risk of adverse maternal, perinatal and infant outcomes. ${ }^{4,5}$ Postpartum IUDs provide a high level of efficacy in the absence of systemic metabolic effects, and ongoing motivation is not required to ensure efficacy once the device has been placed. ${ }^{6}$ Contraceptive counselling is one of the important aspects of postpartum care.

To address the unmet need during the post-partum period the Ministry of Health and Family Welfare, Government of India developed a national strategy to expand PostPartum Intrauterine Device (PPIUCD) services among 
public sector facilities. The aim of this study was to compare the safety, efficacy and complications of postplacental and intracaesarean insertion of Intrauterine contraceptive device.

\section{METHODS}

The present study entitled "Comparative study of IUCD inserted intracaesarean and after vaginal delivery" is conducted in the department of obstetrics and gynaecology,Sultania Zanana Hospital from April 2015 to March 2016. 500 subjects included in the study,250 in normal vaginal delivery group and 250 in caesarean section group.

The present study was carried out on women who delivered at our hospital and underwent PPIUCD insertion. All pregnant women admitted in the labor ward were counseled for different postpartum family planning methods (Cafeteria approach). Those women who chose PPIUCD were told regarding advantages, limitations, effectiveness and side effects related to IUCD. Every woman was screened for clinical situations as per WHO medical eligibility criteria in the antenatal period, as well as in postpartum period. Informed consent was obtained in all clients before insertion. The IUCD (CuT-380A) was placed within 10 minutes expulsion of placenta using Kelly's placental forceps to ensure the fundal placement. Intracaesarean insertion was done manually.

Follow up visit was scheduled at 6 weeks and 6 months postpartum and thereafter as and when necessary. During the follow up visit the women were asked if they had any complaints and a speculum examination was performed to assess if the IUCD strings have descended into the vagina. In a few women in whom strings were not visible in vagina ultrasonography was done to confirm the intrauterine position of IUCD. Findings of the follow up visit were recorded in all clients including expulsion, excessive bleeding per vaginum, pelvic pain, removal, incidence of infection and other side effects. In case women failed to turn up for follow-up, they were contacted through telephone.

\section{Inclusion criteria}

- Women in immediate post placental period (within 10 minute of placental expulsion) or during caesarean section.

\section{Exclusion criteria}

- Women with acute purulent discharge

- Has current, recent pelvic inflammatory disease

- Chorioamnionitis, prolonged rupture of membranes $>18$ hours, obstructed labor, anaemia

- Post-partum haemorrhage.

- Has distorted uterine cavity.

- Has known pelvic tuberculosis, HIV positive women.

- Has genital tract cancer.

\section{RESULTS}

The present study shows that majority of PPIUCD Recipients i.e. $42 \%$ are in the age group of $21-25$ years, $33.6 \%$ users are in the age, $17.2 \%$ users are in the age group of $31-35$ years, $4.6 \%$ are less than 20 years and $2.6 \%$ are more than 35 years (Table 1 ).

Table 1: Distribution of cases according to Age.

\begin{tabular}{|lll|}
\hline Age group (Years) & Number & Percentage \\
\hline $15-20$ & 23 & 4.6 \\
\hline $21-25$ & 210 & 42 \\
\hline $26-30$ & 168 & 33.6 \\
\hline $31-35$ & 86 & 17.2 \\
\hline$>35$ & 13 & 2.6 \\
\hline Total & 500 & 100 \\
\hline
\end{tabular}

In our study majority of PPIUCD clients i.e. $42 \%$ had one live issue. $36 \%, 18.8 \%, 3.2 \%$ had two, three and more living issues. Woman who have three or more living issues were more willing for sterilization (Table 2).

Table 2: Distribution of cases according to Parity.

\begin{tabular}{|lll|}
\hline Parity & Number & Percentage \\
\hline Primipara & 210 & $42 \%$ \\
\hline Para-2 & 180 & $36 \%$ \\
\hline Para-3 & 94 & $18.8 \%$ \\
\hline Grandmulti & 16 & $3.2 \%$ \\
\hline
\end{tabular}

During follow up Bleeding $\mathrm{P} / \mathrm{V}$ found in 37 (14.8\%) women after postplacental insertion whereas they were present in only $23(9.2 \%)$ women after intracaesarean insertion, however this difference was not statistically significant. Pelvic pain was present in $30(12 \%)$ women after postplacental insertion whereas in 26 women $(10.4 \%)$ in intracaesarean insertion. Statistical inference $p$ value $>.05$, the result was not statistically significant. Infection was present in $9(3.6 \%)$ cases in post placental insertion whereas in intracaesarean insertion present in only $3(1.2 \%)$ cases. Statistical inference-p value $>.05$, the result was not statistically significant. Findings at follow up are recorded in Table 3.

Table 3. Clinical presentation at follow up visit.

\begin{tabular}{|llll|} 
Complaints & $\begin{array}{l}\text { Postplacental } \\
\text { group } \\
(\mathrm{n}=250)\end{array}$ & $\begin{array}{l}\text { Intracesarean } \\
\text { group }\end{array}$ & P value \\
$\begin{array}{llll}\text { Bleeding } \\
\text { P/V }\end{array}$ & $37(14.8 \%)$ & $23(9.2 \%)$ & $>0.05$ \\
\hline $\begin{array}{l}\text { Pelvic } \\
\text { pain }\end{array}$ & $30(12 \%)$ & $\begin{array}{l}26 \text { women } \\
(10.4 \%)\end{array}$ & $>0.05$ \\
$\begin{array}{l}\text { Discharge } \\
\text { P/V }\end{array}$ & $9(3.6 \%)$ & $3(1.2 \%)$ & $>0.05$ \\
\hline
\end{tabular}

Incidence of expulsion was more in postplacental insertion which was present in $33(13.2 \%)$ cases while in 
only $17(6.8 \%)$ cases in intracaesarean insertion. This lower expulsion rate after transcaesarean insertion as compared to vaginal insertion may be due to direct placement of IUCD at the fundus during caesarean section. (Table 4.)

Table 4. Expulsion of PPIUCD.

\begin{tabular}{|lllll|} 
True & Post & $\%$ & $\begin{array}{l}\text { Intra } \\
\text { caesarean }\end{array}$ & $\%$ \\
Expulsion & placental & 13.2 & 17 & 6.8 \\
\hline Present & 33 & 86.8 & 233 & 93.2 \\
\hline Absent & 217 & &
\end{tabular}

Statstical inference- $\mathrm{p}$ value $<0.05$ result was statistically significant. These women were informed about IUD expulsion and were advised to use alternative method of contraception. However, no case of misplaced IUCD was reported. Removal rate of PPIUCD was higher in postplacental insertion i.e.43 (17.2\%) cases whereas in intracaesarean insertion removal rate was $8.4 \%$ and this difference was statistically significant $\mathrm{p}$ value $<0.05$. Various reasons for removal of IUCD shown in (Table 5).

Table 5. Reasons for Removal of IUCD.

\begin{tabular}{|lllll|}
\hline $\begin{array}{l}\text { Cause of } \\
\text { removal }\end{array}$ & $\begin{array}{l}\text { Post } \\
\text { placental }\end{array}$ & $\%$ & $\begin{array}{l}\text { Intra } \\
\text { caesarean }\end{array}$ & $\%$ \\
\hline $\begin{array}{l}\text { Pelvic pain } \\
16\end{array}$ & 37.2 & 07 & 33.33 \\
\hline $\begin{array}{l}\text { Bleeding } \\
\text { Social } \\
\text { cause }\end{array}$ & 13 & 30.2 & 06 & 28.5 \\
\hline PID & 01 & 23.2 & 07 & 33.33 \\
\hline Total & 43 & 2.3 & 00 & - \\
\hline
\end{tabular}

Most common cause of removal of PPIUCD in our study pelvic pain and menstrual disturbances. In 16 (37.2\%) cases of postplacental insertion pelvic pain was the cause of removal while in intracaesarean insertion only in 7 $(33.33 \%$ ) cases PPIUCD was removed due to pelvic pain. Other women were successfully treated with analgesics and were reassured. 1 case of removal was reported due to PID in postplacental insertion.

\section{DISCUSSION}

The present study done at Sultania Zanana Hospital, Bhopal, total 500 users participated in this study. The PPIUCD is a highly effective, long acting reversible,cost effective and easily accessible family planning method that is safe for use by most postpartum women- including those who are breast feeding. Majority of cases in our study i.e.75.6\% who accepted IUCD belongs to age group 21-30 years. This indicates that younger women accepted PPIUCD more, realizing the effectiveness of PPIUCD as an effective spacing method.

Alvarez Peyalo et al., also found that the average age of PPIUD acceptors was 20.6 years. ${ }^{7}$ This study shows that among Postplacental group $14.8 \%$ clients had complaints of bleeding $\mathrm{P} / \mathrm{V}$, while who have intracaesaeran IUCD insertion only $9.2 \%$ had complaints of bleeding. Pelvic pain was reported in $30(12 \%)$ women after postplacental insertion whereas in 26 women $(10.4 \%)$ in intracaesarean insertion.

However, incidence of bleeding $\mathrm{P} / \mathrm{V}$ and pelvic pain was more in post placental insertions compared to intra caesarean insertions, but this difference was statistically not significant ( $\mathrm{P}$ value $>0.05$ ). Infection was reported in 9 cases in postplacental insertions and only in 3 cases in intracaesarean group but this difference was not statistically significant.Infection was reported in $4.8 \%$ cases in our study because it was based on self-report not corroborated by microbiological examination.

In a systematic review by Kapp and Curtis the outcome of post-partum insertion of IUD at different time interval was compared. The evidence demonstrated no increase in risk of complications among women who had an IUCD inserted during the post-partum period. ${ }^{8}$ In a study by Shukla et al. using Cu T 200 B in immediate post-partum period, $27.23 \%$ women were found to have heavy bleeding during menstruation. Neither of the women in their study complained of pain in lower abdomen or abnormal vaginal discharge nor did any of them had any sign of PID. ${ }^{9}$

Celen $\mathrm{S}$ et al, reported cumulative rates of bleeding equal to $11.4 \%$ in postplacental insertions and $8.2 \%$ in intracaesarean insertions respectively. ${ }^{7,10}$ Welkovic et al. studied post-partum bleeding and infection after posting placental IUD insertion and found no difference in the incidence of bleeding. ${ }^{11}$ The present study shows that expulsion rate was more in postplacental insertion group i.e. $13.2 \%$ while among intracaesarean group it was $6.8 \%$ and this difference was statistically significant.

In a systemic review by Kapp and Curtis Post-placental placements during cesarean delivery are associated with lower expulsion rates than post-placental vaginal insertions, without increasing rates of postoperative complications. ${ }^{9}$ Chi et. al also found that expulsion rates were lower among intracaesarean insertion group than with postplacental insertion group. ${ }^{11}$ This lower expulsion rate after transcaesarean insertion as compared to vaginal insertion may be due to direct placement of IUD at the fundus during caesarean section.

\section{CONCLUSION}

Thus, from our study it is concluded that PPIUCD is safe, convenient, cost effective, reversible and long term birth spacing method. It should be part of a maternal/newborn/reproductive health package. The government schemes like Janani Suraksha Yojana (JSY) is an opportunity to add PPIUCD into family planning programme and could address the high unmet need for Family planning in India. The increased institutional deliveries are the opportunities to provide women easy 
access to immediate PPIUCD services. PPIUCD has a huge potentiality and scope in India and if widely used it will have strong impact on population control and will prevent unplanned pregnancy and its sequale.

Funding: No funding sources

Conflict of interest: None declared

Ethical approval: The study was approved by the Institutional Ethics Committee

\section{REFERENCES}

1. IUCD Reference Manual for Medical Officers and Nursing Personnel. 2013. Available at https://nrhm.gujarat.gov.in/images/pdf/IUCD_Refere nce_Manual_Nursing_Personnel.pdf

2. District level household and facility survey III 200708 (DLHS III). Ministry of health and family welfare, Government of India. Available at https://mohfw.gov.in/sites/default/files/DLHS\%20III .pdf

3. Conde-Agudelo, A, Belizan JM, Maternal morbidity and mortality associated with interpregnancy interval: cross sectional study. $\mathrm{Br}$ Med $\mathrm{J}$. 2000;321:1255-9.

4. Conde-Agudelo A, Rosas-Bermúdez A, KafuryGoeta AC. Birth spacing and risk of adverse perinatal outcomes: a meta-analysis. JAMA. 2006;295:1809-23.

5. World Health Organization, 2006 Report of a WHO Technical Consultation on Birth Spacing. Available at

http://apps.who.int/iris/bitstream/handle/10665/6985
5/WHO_RHR_07.1_eng.pdf;jsessionid=A7B8568F D9A131B88F0AADE7A3297C01? sequence $=1$

6. Hall JE. The female reproductive system, infertility and contraception, Harrison's principles of internal medicine, $18^{\text {th }}$ edition. Mc Graw Hill; 2011;347:3037-38.

7. Kapp N, Curtis KM. Intrauterine device insertion during the postpartum period: a systematic review. Contracept. 2009;80:327-36.

8. Shukla M, Qureshi S, Chandravati. Post-placental intrauterine device insertion: a five-year experience at a tertiary care centre in north India. Indian J Med Res. 2012;136:432.

9. Celen S, Möröy P, Sucak A, Aktulay A, Danişman N. Clinical outcomes of early postplacental insertion of intrauterine contraceptive devices. Contracept. 2004;69:279-82.

10. Welkovic S, Costa LO, Faúndes A, de Alencar Ximenes R, Costa CF. Post-partum bleeding and infection after post-placental IUD insertion. Contracept. 2001;63:155-8.

11. Chi IC, Wilkens L, Roger S. Expulsions in immediate postpartum insertion of Lippes Loop D and Copper T IUD's and their counterpart Delta devices-an epidemiological analysis. Contracept. 1985;32:119-34.

Cite this article as: Goyal A, Wadhwani R, Agarwal A, Pandey A. Comparative study of IUCD inserted intracesarean and after vaginal delivery. Int J Reprod Contracept Obstet Gynecol 2018;7:2007-10. 